\title{
Acerca de los nombres de las personas (üy) entre los mapuches. Otra vuelta de tuerca.
}

\author{
Further insights on personal names (üy) among the Mapuche
}

\author{
Rolf FoersteR ${ }^{\mathrm{i}}$
}

\begin{abstract}
RESUMEN
No hay consenso entre los estudiosos sobre cómo se construyen los nombres propios mapuches y sus modos de circulación o asignación (ya sea por la línea materna, paterna o una combinación de ambas). A partir de un trabajo etnográfico en Altos Bio Bío pudimos observar un complejo universo de ritos y creencias acerca de los nombres (üy) y cuyo modelo, que llamaremos laku, hipotetizamos puede generalizarse en el tiempo (hacia el pasado) y en el espacio (a la Araucanía). Desde este modelo realizamos una lectura critica de los diversos intentos que, en los últimos cien años, se han realizado para comprenderlo.
\end{abstract}

Palabras claves: Mapuche, Parentesco, Identidad, Nombres Propios.

\begin{abstract}
There is no agreement among academics about how mapuche's given names are constructed and the ways in which they are circulated or assigned (through maternal, paternal or a combination of the two lines). An ethnographic study in Altos Bio Bio allowed us to identify a complex universe of rituals and believes surrounding the names (üy) whose model -which we will call laku-we hypotheticize can be generalized in time (towards the past) and in space (the region of Araucania). Using this model we critically approach the attempts made during the last hundred years to understand the construction, assignment and circulation of given names in mapuche society.
\end{abstract}

Key words: Mapuche, Kinship, Identity, Names.

Departamento de Antropología, Universidad de Chile. E-mail: Rolf22@gmail.com Recibido: Marzo 2010. Aceptado: Mayo 2010. 


\section{INTRODUCCIÓN}

Queremos en este artículo hacer una lectura de los diversos trabajos escritos en el siglo XX sobre los nombres propios mapuches, desde un modelo construido por nosotros a partir de la data etnográfica de una comunidad de Altos Bío Bío: Kauñiku. El tema es de interés, prueba de ello es que la mayoría de los estudiosos de este pueblo han debido enfrentarse al enigma de los nombres (Augusta 1907; Boccara 1999; Catriquir 1990; Catriquir y Durán 2007; Course 2009; Dillehay 1990; Faron 1969; Guevara 1925; Isla 2009; Jiménez 2002; Latcham 1922; Menard 2007; Silva 1984). Esperamos también en esta lectura llamar la atención sobre cómo los datos fuera de Altos Bío Bío y su tratamiento son iluminados por el modelo del laku, en especial las reflexiones sobre la filiación (Menard 2007, Course 2009) y el espacio territorial (Isla 2009).

\section{Altos Bío BÍO Y EL MODELO DEL LAKU}

En el verano de 1976 con Héctor González, Hans Gundermann y Rodrigo Valenzuela iniciamos un trabajo de terreno, que duraría varios años, en la comunidad de Kauñiku de Altos Bío Bío (en adelante ABB). Cada uno de nosotros se abocó a temas diferentes, sabiendo que todos ellos formaban parte de un vestido sin costura. Héctor a la economía, Hans a la religión, Rodrigo a la cocina y yo al parentesco. Vivíamos en la casa de Lucinda Paine y de su madre Ana María Queupil, con ellas y entre todos compartíamos nuestro aprendizaje de la vida social y cultural de esa comunidad. Más tarde se sumaron a nuestra empeño en ABB Fernando Slater, Gilberto Sánchez, Patricia Jerez y, en el 2000, José Isla.

Una de las tantas sorpresas etnográficas con que nos topamos fue la vigencia del sistema tradicional de nombrarse (üy). Los mapuches de Kauñiku no sólo hacían uso de patronímicos, matronímicos y nombres propios (estos últimos provienen del santoral católico), sino que usaban en la vida cotidiana los üy para designar y nombrarse. Los üy (masculinos) no difieren del universo de los nombres usados como apellidos (patro y matronímicos).

Parte de los resultados de esta investigación se encuentra en mi tesis de Licenciatura de Antropología (Foerster 1980). El “dato" fundamental descubierto fue que los $\ddot{u} y$, como norma ideal, como admapu, debían circular entre generaciones alternadas al interior de los linajes: entre laku en el caso de los hombres, entre $k u k u^{1}$ en el caso de las mujeres. ${ }^{2}$ La ejemplificación con los linajes Naupa y Paine evidenció, además, que cada persona compartía 
"su" üy con su lakú, y que rara vez un hombre se lo daba a una persona de otro linaje, que no había, por tanto, un üy común a todo el linaje. Esto sólo operaría con el patronímico, el cual emergió con el sistema reduccional al concordarse que uno de esos $\ddot{u} y$ desempeñara el papel de patronímico. Por otro lado, quedó de manifiesto que los üy de las mujeres, a diferencia del de los hombres, circulaban entre linajes (se le da en su linaje y lo da en el linaje de su esposo), por último que los üy jugaban un papel fundamental en el sistema ritual del nguillatún. Estuvimos conscientes que estos antecedentes ponían en cuestión la tesis de Latcham (1922) sobre el pretendido totemismo mapuche, como también que ampliaba la reflexión de Félix de Augusta (1907) acerca de los nombres.

En 1993 junto a Gundermann (Foerster y Gundermann 1993) encaramos dos cuestiones en torno al $\ddot{u} y$. En primer lugar, su papel en la identidad de la persona y los ritos de entrega del üy: lakutún en el caso de los hombres y katancahuin en el caso de las mujeres. En segundo lugar,

En los nguillatun se realiza una danza llamada tregül purrún (...) y en otras zonas choikepurún (...), a cargo de contingentes de cinco varones de cada linaje o sublinaje alternadamente. En ellas se les anuncia a cada individuo, por las aliadas y consanguineas del grupo, un pequeño cántico que incluye el nombre propio mapuche que son patrimonio de los linajes. Significativamente este cántico (tayel), especificado para cada varón, es llamado kuñpen o kumpell, término que ha servido en otras zonas para denotar a un grupo patrilineal (Foerster y Gundermann 1993:48).

Asimismo explicitamos que era posible que existiera, antes de la implantación del sistema reduccional, dos sistemas o modelos de "entrega" de nombres: el que observamos en Kauñiku y otro ligado al künga o kuga. Al primero lo llamamos modelo mecánico o laku y al segundo aleatorio (véase más adelante a Augusta). Señalábamos en relación a este último que,

Los nombres propios son parte de un sistema de clasificación totémica, dentro del cual cada grupo se regia por un principio de organización patrilineal, poseía un término genérico, kunga o kuga, traducible a especies animales, plantas, minerales, fenómenos y elementos diversos de la naturaleza. Este término se heredaba patrilinealmente. Se trata, al parecer, de un sistema de diferencias objetivamente observables en la naturaleza (especies y clases) y uti- 
lizadas para significar diferencias entre los grupos sociales. En un nivel de menos inclusividad, pero relacionado al anterior, los individuos varones que formaban parte de un grupo de parentesco eran nombrados a partir del nombre genérico o kunga por medio de una particularización de la especie o de la clase, adjetivación o cualificación o aún por medio de elementos en relación de contigüidad. De alli entonces que el nombre propio, agregado al kunga de un individuo, fuera aleatorio (Foerster y Gundermann 1993:41-42).

En el 2004 volví al tema del $\ddot{u} y$ en mi tesis doctoral (Foerster 2004) y en un proyecto Fondecyt (2005-2007), que tenía como centro de investigación las poblaciones mapuches de la costa de Arauco. Mi opinión, fundada en un mejor conocimiento etnográfico y de las fuentes de crónicas y archivos de dicha área ${ }^{3}$, es que el modelo aleatorio posiblemente no existió, lo que encontramos es el modelo de los laku, el que posteriormente fue suplantado por el modelo criollo (nombre propio y apellidos) o se mantuvo en algunas áreas de forma paralela a dicho sistema (como es el caso de $\mathrm{ABB}$ o, como lo constató Faron (1969) en la década de 1950, de las cercanías de Temuco).

\section{LECTURA CRÍTICA A LAS INVESTIGACIONES ANTROPOLÓGICAS DESDE}

\section{EL MODELO DEL LAKU}

Fray Félix José de Augusta, 1907

El aporte más significativo de este sacerdote capuchino, en “¿Cómo se llaman los araucanos?” (de Augusta 1907), es su amplio repertorio de nombres y su traducción al castellano; la manera cómo están compuestos aquellos nombres de dos o tres palabras, los apócopes y los nombres de mujeres (distintos al de los hombres); y cómo la voz künga, ya en desuso, es equivalente a kümmpen ("una adulteración de la expresión Küme pen úi, nombre adquirido de buena manera", de Augusta 1907: 7).

Lo notable de Augusta es que acepta sin miramientos la definición de los jesuitas Valdivia (1684), Havestadt (1883) y Febres (1765), pues ve confirmados sus aciertos en "los libros antiguos de bautismo, en los cuales a menudo el hijo está asentado con otro apellido que el padre al par que los apellidos de los dos se nota el mismo künga" (de Augusta 1907: 7).

Abramos un paréntesis para recordar restituir la mirada jesuita, sobre todo porque tanto Latcham (1922) como Guevara (1925), y más recientemente Boccara (1999), tienen en mente esos antecedentes del cúga o cünga. 
Para el padre Luís de Valdivia,

"tienen los indios otro género de parentesco de nombre, que llaman cúga, como alcuñas de sobrenombres, que ay generales en todas las provincias desde la Concepción en adelante, asi por la costa como por la cordillera y todos se reduzen a veinte que son estos: Antü, amuchi, Cacten, Calquen, Cura, Diucaca, Entuco, Glliu, Gru, Gagen, Huercubue, Yani, Yeni, Luan, Linqui, Mugu, Pagi, Qllvu, Villcún, Vüde. Y no ay indio que no tenga algún apellido destos: que significan: Sol, león, sapo, zorro, etc. Y tiénense particulares respecto unos a otros, los que son de un nombre se llaman quinelacu" (Valdivia 1684:70-71).

Es extraño que Luís de Valdivia, con su conocimiento de la lengua y del mundo de los mapuches al sur del Bío Bío, sostenga la tesis de que existían sólo veinte cúga. Basta leer su extensa documentación sobre la guerra defensiva en la que los nombres de los caciques exceden ese universo de nombres para desmentir su propia afirmación.

Los antecedentes del padre Febrés, a mediado el siglo XVIII, si bien amplían el juego "político" en torno a los nombres, lo limitan al considerar que al menos el linaje o familia tiene un mismo cüga,

"nótese aqui que sus nombres son compuestos de dos palabras, de las cuales, la una es el nombre propio de su linaje o cúga, o digamos apellido, como Lavquén, Leuvu, Nahuél, Pagi, Gurú, Calquín; esto es mar, río, tigre, león, zorro, águila, etc. $Y$ aunque en los coyagtunes se nombran con el nombre entero, más en sus pláticas familiares suelen nombrarse con solo la primera palabra y una silaba o letra de la segunda, v.g.: Vuchalav por Vuchalavquén, mar grande; Millaleu por Millaleuvu, oro del río o río del oro; Curiñam por Curiñancu, aguilucho negro; lo cual al principio no deja de causar alguna confusión" (Valdivia 1765:92).

La misma opinión de Febrés la tiene Havestadt,

"Cúga, raza, linaje, estirpe, familia, nación. Además el nombre que toman de las aves, cuadrúpedos, serpientes, peces, piedras y cualquiera otra cosa animada o inanimada. En primer lugar toman en cuenta el nombre o sobrenombre de su cúga o familia y raza; v.gr.: tiene alguien por cúga el nombre Hueque, que significa carnero chileno; considerando en seguido sus adjuntos, propiedades etc. llama á algunos de sus hijos Liúheque, carnero blanco, al otro 
Curúhueque, carnero negro; al otro Neculhueque, carnero que corre; al otro Llaufülemu sombra silvestre, porque el carnero principalmente en verano busca la sombra de los árboles etc. Otro tiene por cúga el nombre Pañi, León. Por eso llama a uno de sus hijos Vûtapañi, León grande; a otro Loncopañi, Cabeza de León; a otro Huilipañi, Uña de león; a otro Huaiquipañi León con hastas, etc. Cuando se juntan varios nombres, el nombre cúga suele colocarse en último lugar, aunque no siempre, pues hay que atender a las circunstancias. Los nombres de las mujeres son las más veces ridiculos: por eso se avergüenzan de manifestarlos. Aun los mismos Padres Misioneros les imponen el nombre de alguna familia, la cual los cuenta entre sus parientes, y como insertados en su estirpe. A mi pusieron el nombre de Huaiquilafquen. Huaiqui lanza, es nombre de familia, y se me dio porque soy de alta estatura; Lafquen, mar, porque respecto de ellos soy ultramarino" (Havestadt, citado en Augusta 1907: 5).

Así la impronta de los jesuitas, abocados a la lengua mapuche (Valdivia, Febrés y Havestadt), ha sido determinante en la identificación del linaje, o de un grupo de patriparientes, con un cúga. De todos modos, no deja de ser sorprendente que el modelo del laku no fuera descrito por ellos, sabiendo el vínculo que se generaba por las donaciones de nombres entre laku4. Sorprendente, porque suponemos que estos tres jesuitas tenían las mismas competencias lingüísticas y etnográficas. Tendríamos entonces que reconocer que no siempre tuvieron éstas (por ejemplo, la demostración que da Havestadt sobre su nombre es impecable lingüísticamente, pero etnográficamente es contradictoria: uno no sabe si el cúga dado proviene de una familia que se lo donó, o por ser alto concluyeron que debía pertenecer al cúga Huaiqui, o porque el nombre más adecuado para una persona alta era Huaiqui). Cerremos el paréntesis.

Al no tener en mente el modelo laku, Augusta especula acerca del modo en que se construye el nombre individual (ya que el kúmpen es heredado por línea paterna),

"Donde concurren dos palabras a formar el nombre, una de ordinario viene a ser el kúmpen o sea apellido de la familia, mientras que la otra sirve para distinguir el individuo. Cual sea lo determinante en la selección del nombre individual, no hemos podido averiguarlo. Según nos han asegurado unos indigenas, lo seria únicamente la eufonía: no combinan con el kúmpen cualquier palabra 
o número; p.ej. Pura pangi ocho leones, no sería grato a su oido. Sin embargo no podemos desasirnos de la opinión de que en muchos casos exista un conjunto ideal entre el nombre y su portador reflejándose en el primero una cualidad del individuo o un suceso doméstico u observado en la naturaleza que coincidia con su nacimiento" (de Augusta 1907: 7).

Se trata del modelo aleatorio, aunque apegado a circunstancias "naturalistas", "propio de los hijos de la naturaleza”, y sería válido tanto para el "apellido de la familia", como para el "nombre individual",

"Mientras los apellidos de las naciones civilizadas hacen gran papel los nombres de oficios, como en alemán los sastres, molineros, zapateros o de dignidades, como los condes, principes, reyes, mayores, emperadores. El conjunto de los apellidos araucanos da a conocer que aqui se trata de una nación en estado natural, la cual vive en continúo contacto con la naturaleza y saca de ella sus ideas. Por lo tanto encontramos aqui rica colección de cuadrúpedos pájaros, gusanos e insectos, piedras, metales, rio y mar, creciente y decreciente, bosque, árbol y flor, sol y luna, partes del cuerpo. El indio cuenta en los apellidos lo que ve en la naturaleza, lo que le da gozo, lo que observa y tiene en estima, no falta tampoco cierto humor infantil e inocente que es propio de los hijos de la naturaleza" (de Augusta 1907: 8).

Ricardo Latcham, 1922

Fue posiblemente Latcham el primero en mostrar y destacar que los nombres de los hijos no eran los mismos que el del padre y en suponer (sin demostrar) que eran coincidentes con el de la madre. Esto último era un dato crucial para su hipótesis de que los "indios de Chile" estaban transitando de la filiación materna y del totemismo (el tótem — cüga-como "ser tutelar y protector del fundador del clan", distinto "al antepasado fundador del clan") al patriarcado5,

"...el sistema de apellidos empleados por los indios de Chile, y entre ellos los Araucanos, se originaba en los tótemes; pero ningún cronista ni ningún documento dice si los apellidos (tótemes) se heredaban de la madre o del padre. Todos los que han escrito sobre el tema han supuesto, sin mayores investigaciones, que eran patronimicos.

No hay duda que entre los araucanos, al menos los del norte del rio Cautín, el padre era jefe de familia a comienzo del siglo XVI... 
Todo esto haría suponer que los hijos heredarian el tótem y apellido del padre, empero nuestras investigaciones nos demuestran lo contrario.

Al contar su descendencia por el lado paterno, el tótem y apellido de los hijos sería iguales a los del padre, y en ningún caso que hemos podido establecer ha sucedido esto. Al registrar los nombres de los indígenas a que hemos hecho referencia al hablar de las distribuciones de tótemes, tuvimos especial cuidado de apartar los que eran padre e hijos, y jamás correspondian en cuanto a apellidos...

Todos estos hechos, a nuestro ver, solamente pueden significar que prevalecía por todo el pais el sistema de filiación materna, que da a los hermanos uterinos el mismo apellido, el que es en todo caso diferente que él del padre" (Latcham 1922: 322, 323 y 325).

Latcham entrega varias pruebas sobre la herencia materna del tótem: "la heterogeneidad de los apellidos en cada agrupación" (Latcham 1922: 331) y también el vínculo laku,

"A menudo se ve aparecer en las crónicas y documentos el nombre de un individuo ya muerto, ocupando el mismo puesto de cacique o principal. Pero éstos no eran hijos aun cuando podian ser sucesores del difunto. Tiene una explicación fácil, y es otra prueba de la filiación materna.

En este mismo capitulo hemos hablado del cacique Tipitureo de Peteroa, y de su nieto que también se llama Tipitureo y era cacique del mismo lugar. Existe prueba documental de ese parentesco" (Latcham 1922: 333).

El autor da otros ejemplos donde "abuelo y nietos" llevan el "mismo nombre y apellido" (Latcham 1922: 333 y 334). La explicación que da es la siguiente,

"Muchas veces, por alianza de familias, se casaban, en cada generación, los hijos e hijas de dos grupos totémicos; perpetuando asi, en cada grupo, ambos apellidos. Esta era costumbre bastante general, y cuando el tótem del abuelo era igual al de su nieto primogénito se ponía a éste el nombre también de aquél, especialmente cuando el abuelo era o habia sido hombre de nota. De alli se deriva la denominación lacu (de un mismo nombre) que se traduce generalmente por abuelo y que también significa tocayo" (Latcham 1922: 334). 
Sabemos que el intercambio matrimonial entre los mapuches era del tipo generalizado (matrilateral) y no restringido (bilateral) ${ }^{6}$, de allí que la explicación de Latcham no tenga sustento (para darle coherencia a su argumento traduce la voz laku como abuelo y no como un término recíproco entre generaciones alternadas de filiación paterna).

Como se puede apreciar, Latcham tenía todos los elementos etnográficos para construir el modelo de los laku, pero su apego a las teorías evolucionistas se lo impidió. Por último, recordemos que le faltaba a su argumento el dato de los nombres de las mujeres para así verificar positivamente su hipótesis, pero no lo encuentra porque: "fue la costumbre que tenían los indios de ocultar los nombres de las mujeres... Por consiguiente, no había manera visible y fácil para apreciar el hecho de que el tótem y apellido se deriva de la madre" (Latcham 1922: 334-335). Latcham aquí se equivoca etnográficamente, recordemos que en $\mathrm{ABB}$ el sistema que regula la donación de los nombres de las mujeres es de intercambio entre mujeres (una mujer jamás da su nombre a un hombre) y entre generaciones alternadas, y este es sin duda el modelo que reguló el intercambio de nombres en la cultura mapuche previo al sistema reduccional.

\section{Guevara, Tomás, 1925}

De la extensa obra de Guevara, las referencias a los nombres de las personas se encuentran mayoritariamente en su obra Chile prehispánico (1925). Crítico a la tesis de Latcham (1922) sobre el totemismo y la filiación materna, señala que para aceptar la afirmación de que los hijos heredaban el nombre de la madre, había que conocer el nombre de éstas y que "sin ese dato, la aserción cae por su base". Para Guevara, en cambio,

"La verdad es otra en cuanto a esta variación de los nombres de los padres. En el siglo XVIII $i$ en el pasado se daba a los hijos el nombre del padre, de algún pariente o de personas extrañas a la familia.

Asi para perpetuar el recuerdo de los antepasados, se ponia a uno de los nietos el nombre del abuelo, i para conservar las tradiciones de la parentela, el padre daba a sus hijos las designaciones de sus tíos. Solía poner también a otro, para honrar a la familia, el nombre de algún personaje de orijen español de notoriedad en el territorio indígena ligado con él por una amistad estrecha.

En el siglo XIX persistía este sistema de apellidarse. Los hijos tomaban de ordinario el apellido del padre, pero en muchas ocasiones, 
éste les ponia el de algún pariente, como el de un tio, de un hermano, primo, cuñado, etc., o el de un lacu, padrino; el de un amigo de prestijio; nunca el de la madre. A veces les daba el de amigo españoles, como Riquelme, Sandoval, Romero, López. Las mujeres tomaban comúnmente el de una tía paterna o materna i a veces de alguna pariente querida i no el de la madre" (Guevara 1925 TI:279).

Las observaciones de Guevara poseen el mérito de tener como respaldo no sólo su conocimiento de la documentación colonial y republicana, sino también etnográfica gracias a su amistad y trabajo con numerosos mapuches, muchos de los cuales eran descendientes de lonko y/o ulmen.

Destaquemos de su cita tres cuestiones. La primera que los nombres de hombres y mujeres pertenecen a dos universos distintos y que no se mezclan. En segundo lugar, que el padre, en el siglo XVIII como "en el pasado", tenía la libertad de dar a uno de sus hijos su nombre. Lamentablemente no entrega datos sobre ello, y el único que proporciona es del siglo XIX -familia Cayuleo- (Guevara 1925 T.I:279-280); tampoco aporta antecedentes de donaciones hechas por miembros de la misma generación del padre (hermano, primo, cuñado). La tercera es la dimensión "política" de las donaciones de los nombres, siendo su primera referencia al laku: "para perpetuar el recuerdo de los antepasados, se ponía a uno de los nietos el nombre del abuelo"; y la segunda, a personajes fuera del linaje: "Solía poner también a otro [hijo], para honrar a la familia, el nombre de algún personaje de orijen español de notoriedad en el territorio indígena ligado con él por una amistad estrecha" (Guevara 1925 T.I:279-280).

Louis Faron, 1969 y 1977

El trabajo etnográfico de Faron, a comienzos de la década de 1950, en las cercanías de Temuco, constató dos hechos pertinentes al modelo del laku. El primero referido al lakutún,

"Poco después del nacimiento los padres le dan el nombre al niño sin ninguna ceremonia. Idealmente, los niños reciben otro nombre cuando tienen cinco años más o menos. Se le da por medio de una ceremonia, en un ritual simple llamado lakutún, ya que el nombre es dado por abuelo paterno o por algo que tome su lugar, es decir, otro anciano del linaje. La ceremonia del nombre incluye una fiesta y bebida a la que invitan a los parientes y amigos. El dia del nombre se celebra anualmente. Se dice que los lazos de paren- 
tesco entre las generaciones alternadas se refuerzan y se simbolizan cuando se otorga al niño el nombre del abuelo" (Faron 1969:159).

Lamentablemente la cita de Faron no permite dilucidar si se trata del nombre propio mapuche o winka, pero sin duda el nombre del abuelo donado es el $\ddot{u} y$. La segunda observación de Faron (1977) se encuentra en su obra sobre la religiosidad mapuche y apunta a la particular relación que se establece entre generaciones alternadas gracias a la donación del nombre. ¿Qué se juega en esa donación?,

"No es corriente que el abuelo narre su propia vida y experiencias como tema de lecciones sobre la manera correcta de vivir, sino más bien repite lo que aprendió de su padre y de su abuelo. Es posible que muchos de los fundamentos del comportamiento, tanto positivos como negativos, de la cosecha del siglo XIX, aún sean transmitidos de esta forma. Este es un fenómeno muy corriente entre los actuales mapuche y que está intimamente relacionado a la propiciación de los espiritus ancestrales, la idea que el hombre engendra su prole para su abuelo. Esta continuidad está expresada en el uso reciproco del término laku entre generaciones alternadas, en el lakutun (rito para dar nombres) en el cual el abuelo le confiere un nombre al nieto, y en la asociación ritual de las palabras kume laku pu am, que podrian traducirse como 'espiritus benéficos de mis abuelos'. Este es un concepto, o un punto de vista del mundo, que sirve para comprimir el tiempo dentro de los límites del marco del linaje y asi conectar más intimamente a los vivos y a los muertos. Es una noción que no percibe el que se esté violentando a la historia por la omisión de fijar en el tiempo los eventos históricos cruciales, o aun de amontonar o presentar fuera de secuencia los eventos sobresalientes de los mapuches. En este caso, a causa de este enfoque no histórico del universo, se produce la impresión de que el tiempo no pasa y de que todo es lo mismo, un ambiente intelectual que facilita la comprensión de las genealogías y su manipulación hacia estructuras más solidarias" (Faron 1977: 39-40).

En síntesis, el aporte de Faron confirma, para la zona central de la Araucanía (Temuco, Roble Huacho), el modelo del laku y su nexo con el sistema ritual. 
Silva parte de la misma data etnohistórica de Latcham y Guevara: la no coincidencia de los nombres entre los hermanos y de éstos con sus padres. Su aporte radica en proponer la hipótesis de la doble filiación, que es una suerte de síntesis abstracta de los principios matrilineales y patrilineales sustentados por Latcham y Guevara: los hermanos tendrían una raíz común, (el mentado cuga) aportado por el linaje del padre, y un diferenciador dado por el linaje de la madre. Sabemos ahora, gracias al modelo del laku, que esta hipótesis no tiene aplicación para el sistema mapuche.

\section{Martín Alonqueo, 1984}

En su obra Mapuche ayer-hoy este autor es muy preciso sobre la vigencia, en el pasado reciente, del laku como modelo: "El sistema de sucesión o de encadenamiento de nombre era y es el laku que consiste en tomar o colocarse el nombre del abuelo, tíos y otros parientes en ambos sexos en su respectivo árbol genealógico" (Alonqueo 1984:23).

Al igual que Félix de Augusta, Alonqueo aborda el "origen" de los nombres, éstos provendrían de la "toponimia del lugar", de los "abuelos, tíos y parientes", así "el nombre toponímico que tomaba, significaba poesía y canción relacionada con la acción del ser inteligente con sus cualidades determinativas de ciertos seres espirituales y materiales que ellos sentían, traduciéndolos en nombres" (Alonqueo 1984:15). Ordena en doce grupos los nombres, ya sea que estén "relacionados": "con el saber o la luz", "con la luz reflejada en un objeto", "con el firmamento", "con los animales", "con la velocidad, movimiento, carrera", "con el cóndor", "con los reptiles", "con las piedras", "con la alegría, con la salud", "con la luz artificial", "con la toponimia” y "con la flores" (Alonqueo 1984:16-23).

Por último, respecto a las transformaciones del sistema, señala que el "contacto con la civilización occidental... obligó [al mapuche] a tomar el nombre cristiano de un santo, de un padrino", con lo cual "experimentó grandes cambios en la nomenclatura mapuche... [y] empezó a desmoronarse la sólida y férrea socialización y parentesco del árbol genealógico mapuche" (Alonqueo 1984:23). 
Tom Dillehay, 1990

El aporte de este autor se centra fundamentalmente en la vinculación de los nombres propios con la "cosmovisión" (wenumapu) y con la configuración socioespacial pautada de los linajes y familias en el nguillatún (1990). Dillehay sostiene, en primer lugar, "que existe una estructura ecológica simbólica reflejada en el significado y el orden de la nomenclatura (o nombre kunga) familiar a lo largo de la forma de U" (Dillehay 1990:101). En segundo lugar, que esa estructura tendría la siguiente disposición,

"Trasladándose desde el oeste a la base de la forma de U por los costados hacia el extremo este, la nomenclatura familiar toma nombres comunes de elementos naturales especificos (e.g., caracteres celestiales, carnivoros, herbivoros, plantas, piedras y asi sucesivamente) del orden trófico ecológico de la región. Es decir, las formas ecológicas mayores constituidas por los carnivoros ocupan el extremo oeste o lado superior del campo, en tanto que en el orden de rango inferior están los animales herbivoros y luego las plantas y lo inorgánico"(Dillehay 1990:101).

En tercer lugar, una homología entre esa estructura y los últimos cuatro planos verticales del wenumapu:

"El orden de la nomenclatura en el campo nguillatún horizontal parece ser paralelo al orden ecológico diseñado en los cuatro planos verticales del espacio del wenu mapu. Así, aqui hay una estructura homóloga en el sentido de que las relaciones tróficas pautadas entre los caracteres ecológicos de la nomenclatura linaje-familia en el nguillatún reflejan las relaciones entre las partes correspondientes en los cuatro planos del espacio de wenu mapu" (Dillehay 1990:101).

Dillehay es muy claro al señalar que este "modelo", o "patrón tradicional", es una reconstrucción de cómo fue en el pasado, que hoy la

"mayoría de los informantes... no son conscientes de la existencia de un patrón ecológico como parte del ordenamiento y ubicación de los apellidos ancestrales o de familia", como también que "ya no existen los patrones de ubicación de las familias y linaje siguiendo el ordenamiento y la jerarquía tradicionales, o quizás solamente aparezcan en unos pocos sectores de la cancha de nguillatún. Después de mapear más de 100 canchas, pude observar que solamente 
en 17 de ellas existía un patrón de ubicación completo o parcial, y una de esas canchas fue la de Cherquenco" (Dillehay 1990:102).

Esta situación de pérdida se explicaría por los "procesos de aculturación (fragmentación de los grandes linajes y movimiento forzado producto del sistema de reducción) de los últimos 100 años" (Dillehay 1990:102). Más adelante precisa que este proceso de "aculturación" habría comenzado en el siglo XVI (Dillehay 1990:104).

Sin duda la propuesta de Dillehay (1990) es muy provocativa, pero lamentablemente el universo de los nombres propios, de los laku, se mueve, como hemos visto, bajo otros principios (uno de los cuales cuestiona la existencia de un kuga para el "linaje"). Existen, sin duda, relaciones homológicas entre la disposición espacial de los grupos parentales en una zona y su ubicación "posterior" en el nguillatún, como también son relevantes los laku en dicha ceremonia, entre otras cosas, porque en ella se trata de vincular a los vivos con los antepasados (es decir entre laku), pero de allí a las elucubraciones de Dillehay hay una gran distancia. La hipótesis de este autor tiene mucho de poesía new age y de fantasía, lo que no está mal para los lectores ansiosos de esas ofertas, pero se desmorona cuando se tiene presente el sistema de las donaciones de nombres en la sociedad mapuche.

\section{Desiderio Catriquir y Teresa Durán, 1990 y 2007}

Para estos autores existirían tres formas de adjudicación de nombres,

"la más relevante habría sido el parentesco, que se plasmaba en la ceremonia del lakutún, a través de la cual el padre, tío o pariente transmite su nombre (kümpen o Kugna) a su descendencia". La segunda es aquella en que "un individuo podría también acceder a través de la amistad que el padre tenía con otra persona. A esta forma se la denominaba ayütun üy". La última, "probablemente menos valorada que las anteriores, era el ñimitun üy, protagonizada por aquellos individuos a quienes no se les conocía el padre" (Catriquir 1990:264).

Los autores construyen un modelo ideal de "acuerdo a la bibliografía" y al trabajo de Catriquir (1990) en Panguipulli en 1980, y que se resume en el cuadro 1 . 


\begin{tabular}{|l|l|l|}
\hline Vínculo social & Mapun üy & Sexo \\
\hline Chau üy (nombre del padre) & Mañkewal & Hombre \\
\hline Yal üy (nombre de hijos) & Mañkewal & $"$ \\
\hline \multirow{2}{*}{} & Kalliwal & $"$ \\
\cline { 2 - 3 } & Melliwal & $"$ \\
\cline { 2 - 3 } & Kallfüwal & $"$ \\
\cline { 2 - 3 } & Antüwal & Mujer \\
\cline { 2 - 3 } & Lefitray & Maja \\
\cline { 2 - 3 }
\end{tabular}

Cuadro 1: Modelo ideal de adjudicación del nombre en la sociedad mapuche tradicional (extraido de Catriquir 1990: 265).

Table 1: Ideal model for the acquisition of personal names among Mapuche traditional society (extracted from Catriquir 1990: 265).

El comentario a este cuadro por los autores es el siguiente,

"se aprecia que el elemento fijo llamado Kugna o kümpem se mantiene en la descendencia. Este elemento va acompañado por descriptores individuales asignados a los hijos. La variación total de esta estructura se daria para las hijas, quienes adoptaban nombres sólo propios a su género" (Catriquir 1990:265).

Como se aprecia, esto es una vuelta al modelo aleatorio, lo que implica una serie de dificultades. La primera, el modelo de adscripción que Catriquir y Durán presentan en el cuadro 2, como "aparentemente desestructurado", es el que también observamos en $\mathrm{ABB}$, es decir, donde el nombre de los padres no es el mismo que el de sus hijos, al provenir de la generación alternada ascendente, de los laku-kuku:

\begin{tabular}{|l|l|l|}
\hline Vínculo social & Mapun üy & Sexo \\
\hline Chau üy (nombre del padre) & Kolüpang & Hombre \\
\hline Yal üy (nombre de hijos) & Ngeyju & Mujer \\
\hline \multirow{2}{*}{} & Ayikuy & $"$ \\
\cline { 2 - 3 } & Wentelew & Hombre \\
\cline { 2 - 3 } & Nangkupang & Mujer \\
\cline { 2 - 3 } & Neyüwal & Hombre \\
\cline { 2 - 3 } & Mashall & Mujer \\
\cline { 2 - 3 } & Pangilef & Hombre \\
\cline { 2 - 3 }
\end{tabular}

Cuadro 2: Modelo de adscripción del nombre, aparentemente desestructurado (extraido de Catriquir 1990: 266).

Table 2: Model for the acquisition of personal names. Apparently disrupted (extracted from Catriquir 1990: 266). 
En segundo lugar, deja en un vacío el asunto de los nombres de las mujeres (el modelo laku lo resuelve: es un tema de género, proviniendo de la generación de las abuelas paternas, $k u k u$ ). En tercer lugar, el modelo aleatorio funciona como "ideal" y sólo sirve para un grupo restringido de descendientes. ¿Cuántos "descriptores" conocemos para los kugna? Reconozcamos que siempre es un número limitado y que debe enfrentar serios problemas para poder abarcar a un patrilinaje con amplia descendencia. Por último, el modelo ideal no puede dar cuenta de las otras dos formas de adjudicación ayütun üy y ñimitun üy-que altera, en la segunda generación, dicho modelo.

La ventaja del modelo aleatorio es, según nuestra opinión, que deja abierta la puerta a la creatividad en la construcción de los nombres,

"Conjuntamente con esta estructura debió funcionar una de tipo cultural a partir de los distintos criterios que la sociedad usó para seleccionar y adjudicar los nombres. En ese proceso habría tenido especial importancia el contexto ecológico, pero más que nada la discriminación cognitiva y socioétnica que los mapuches protagonizaron respecto de este contexto. Así, la naturaleza se re-creaba en el proceso de formulación de los nombres, tanto como se expresaba la creatividad de los miembros del grupo respecto de distintos tipos de fenómenos, no necesariamente vinculados a elementos propios de la naturaleza, ya que también se consideraban aptitudes, estados de ánimo, etc." (Catriquir 1990:263).

Es sobre este aspecto de historicidad que los autores insistirán en su trabajo del 2007,

"En nuestro estudio, el küga se concibe por la gente en tanto estado $y$ acción y representan formas de establecer relaciones con los animales de un modo metafórico en un ecosistema dado. Todavia más allá, el rastreo de tales significados nos orienta hacia la historia del asentamiento de los grupos familiares en el territorio, el contacto entre ellas, asi como los simbolismos subyacentes a esa relación y a los cambios culturales en relación a esa historia" (Catriquir y Durán 2007:385).

En el modelo laku la creatividad del nombre es indiferente (su preocupación es la adjudicación), en cambio para el modelo aleatorio es central, porque tiene como eje el motivo que todos los nombres del linaje comparten el kugna o kümpem y por ello hay que "crear" la diferencia en esa unidad. Pero, el asunto se complica, porque si se crea de forma permanente (para 
cada hijo e hija) desaparece la relación de donación del nombre, ya sea entre padres e hijo, o entre generaciones alternadas patrilineales (en el caso de los hombres).

También estos autores abordan las transformaciones que se produjeron con la implantación del sistema reduccional, una de estas "consistió en inscribir al mapuche radicado con el nombre cristiano que probablemente ya tenía, agregándose por apellido paterno el nombre (üy) tradicional del padre y por apellido materno, el nombre tradicional del padre de la madre" (Catriquir 1990:267). Añaden también que,

"Algunos individuos, pese haber quedado con nombres externos, han mantenido vigente sus mapun üy, empleando el winka üy sólo como medio de interacción con la sociedad no mapuche. Este hecho de resistencia cultural lo hemos podido comprobar en el trabajo de campo realizado en 1980 en la zona de Panguipulli. Alli, el nombre personal tradicional estaba vigente en personas nacidas en 1920 y aun hoy se encuentran mujeres que se identifican y se les identifica por su mapu üy (Catriquir 1980). Esto también se comprobó recientemente en el sector de Wapi y Puerto Dominguez, cuando continuamos con esta investigación"(Catriquir 1990:272).

\section{Guillaume Boccara, 1999 y 2007}

La tesis doctoral de Boccara es el esfuerzo más sistemático por reconstruir la historia de los reche-mapuche desde el siglo XVI al XVIII, por lo cual el asunto del cüga no podía estar ausente. Sus comentarios a las fuentes y a la hipótesis de Latcham (1922) sobre el "complejo totémico", nos parecen muy pertinentes. No obstante, sus conclusiones relativas a los vínculos que se generan en la adjudicación de los nombres nos parecen contradictorias y la razón es simple: opta simultáneamente por los dos modelos, el del laku (genera relaciones diádicas entre laku, "abuelo paterno a nieto") y el aleatorio (un cüga común que "tiende a formar unidades: un grupo no localizado de parientes políticos”),

"A partir de este conjunto de datos... podemos plantear la hipótesis de que el cüga se transmite patrilinealmente o, más precisamente, que estos nombres personales transmitidos de abuelo paterno a nieto tienden a formar unidades (patrilinajes o patriclanes) no localizadas en generaciones alternadas. Las fuentes consultadas no mencionan distinciones entre las ramas primogénitas y las cadetes en la atribución de los nombres, y tampoco sabemos si los emble- 
mas clánicos y los seres que les están aparentemente asociados son objeto de culto. De la misma manera, ignoramos si hay prohibiciones alimentarias que acompañan la pertenencia a un cüga. Todas estas interrogantes son aqui mencionadas con el fin de poner en evidencia que las afirmaciones de Latcham, según las cuales existía un complejo totémico que aliaría exogamia y prohibiciones alimentarias, no descansan sobre ningún fundamento documental serio. \{p.57\} Tomando en cuenta las fuentes disponibles, vemos que el problema queda por completo sin resolver y que sólo podemos emprender una nueva dirección planteando la hipótesis de que el cüga remite a un parentesco de otro tipo, más bien político o ceremonial. Es lo que nos sugiere una descripción de Rosales, en la cual se observa que queda a la voluntad de los indigenas tomar o no el nombre del Padre Alonso del Pozo con el fin de que éste sea un lacu: "que le pusiese su nombre para que fuese su lacu, que es palabra de parientes, lo que estiman mucho los indios el ser de un nombre". El cüga, entonces, haría referencia a un grupo no localizado de parientes politicos (afinidad y consanguinidad actuando quizá paralela pero no necesariamente) que demostrarían una particular solidaridad en periodos de conflictos y tendrian a la cabeza a un individuo principal. Pero, evidentemente, esto no es más que una hipótesis y la pregunta queda abierta a futuras investigaciones" (Boccara 2007:62-63).

No obstante esta prudencia en su artículo de síntesis sobre la etnogénesis mapuche, sostiene que las transformaciones estructurales se expresaron también en la política de los nombres de los cacicados:

"Para calificar a estos nuevos caciques es más indicado hablar de un chief que de un big man, precisamente porque las cargas y los estatutos tienden a volverse hereditarios. En su gran mayoria, los apoulmen y ulmen eran hijos de caciques. También, el primogénito del matrimonio primario heredaba el nombre de su padre. Por eso, aparecian patrilinajes localizados y emergían unas suertes de dinastías como los Namcu de Angol, los Lemu de Colue y los Vilu de Moquegua" (Boccara 1999:452-453).

Lamentablemente Boccara aún no ha publicado los antecedentes que nos permitan acceder a "esas suertes de dinastías" y cuando uno va a las fuentes etno-históricas de esas zonas lo que encuentra es más bien el modelo del laku que el de los "Ńamcu, Lemu, Colue y los Vilu". 
La reflexión de Jiménez se elaboró teniendo en cuenta los aportes de algunos de los autores ya citados, y no estando conforme con ninguno de ellos, propone como hipótesis no una variante de la doble filiación, sino un sistema de "filiación diferenciada". La idea es que "en el seno de familias poligínicas, donde se hacen distinciones entre la esposa principal y las esposas secundarias" (Jiménez 2002: 8), los "los hijos de la primera esposa eran los únicos que podían recibir el cuga paterno" (Jiménez 2002:13), los hijos de la segunda, en cambio, obtenían el materno.

El principal documento que utiliza el autor para levantar esta hipótesis es del año 1787. Se trata de un anónimo, escrito en el contexto del breve cautiverio del obispo Francisco José Marán, relativo a las costumbres de los lafkenche,

"El hombre es señor y la mujer esclava. Coavita por semanas y durante ellas aquella con que está deve darle de comer y ensillarle su cavallo si necesita salir afuera. El selo entre ellas suele causar sucesos funestos.

La primera gosa de preferencia y su prole lleva el apellido paterno y las otras el materno" (Jiménez 2002:6).

Según Jiménez "Esta forma de transmisión diferencial de los 'apellidos', ayudaría a explicar satisfactoriamente la anomalía señalada en su momento por Latcham sobre la existencia, en el siglo XVI, de familias en las que los padres e hijos no comparten el mismo cuga" (Jiménez 2002: 8).

Señalemos dos problemas a este planteamiento: la idea de un mismo cuga entre hermanos, como hemos visto, no está demostrada y, por otro lado, que una mujer pueda dar su nombre a un hombre (a sus hijos varones) es imposible. Por último, la data etnohistórica y etnográfica se acopla mejor al modelo del laku que a la filiación diferenciada.

Magnus Course, 2008

La obra de Course (2009), Mapuche Ni Mongen. Individuo y Sociedad en el Sur de Chile, es una visitación renovada a las redes sociales mapuche enmarcadas en las relaciones parentales de la afinidad y la consanguinidad (descendencia), y su contrastación con la sociabilidad del intercambio. Su fundamento empírico es un largo trabajo etnográfico en la zona del Budi, y su idea central es cómo la sociabilidad del intercambio, de la descendencia 
(küpal) y de la afinidad (küpal nuke püle) constituyen a "la persona como un único e irreductible 'individuo'”. Se trata, entonces, de la tensión entre las relaciones "dadas" del parentesco y aquellas que el sujeto puede crear a lo largo del tiempo. Es bajo este techo "que el proyecto de vida mapuche es necesariamente centrífugo - una expansión constante de relaciones a través del tiempo y el espacio-", haciendo de la autonomía personal una realidad "sacrosanta para los hombres mapuche" (Course 2009:71).

¿Cómo entender el $\ddot{u} y$ en este contexto? La reflexión sobre la sociabilidad de la descendencia (küpal) ha sido uno de los ejes del debate: ¿los mapuches se valen de la descendencia para formar grupos (linajes)?. La riqueza de la obra de Course radica en que aporta una detallada descripción y reflexión sobre lo que hoy significa el küpal en el marco del sistema reduccional. Por un lado, sirve para explicar las características de las personas, las que son heredadas de sus cuatro abuelos: "los mapuche reconocen parentesco consanguíneo bilateralmente, ya que la influencia del küpal es transmitida a través de las cuatro 'raíces' de la persona" (Course 2009:65), pero también para dar cuenta de las características físicas y del comportamiento de las personas, de la herencia de roles y del poder espiritual. El autor precisa que,

A pesar de la naturaleza esencialista del küpal, éste, sin embargo,
sólo se manifiesta como el resultado de las interpretaciones de la
gente, interpretaciones que están en sí mismas basadas en relacio-
nes.. En resumen, la agencia individual puede ajustarse, ignorar
o superar cualquier küpal que la persona haya recibido, pero no
puede cambiarlo" (Course 2009: 65).

Por otro lado, el küpal como relación entre personas, "la gente usa el concepto de küpal de manera mucho más extensiva para referirse a relaciones agnaticias, dando así a la expresión un sesgo patrilineal" (Course 2009: 65). Se trata del kiñe küpal: "a pesar de la naturaleza dispersa y amorfa de todos aquellos que comparten un küpal, las relaciones paradigmáticas de lo que he llamado sociabilidad de tipo küpal ocurren entre hombres patri-parientes y co-residentes en una misma reducción" (Course 2009: p.66) ${ }^{8}$. Es justamente por esta co-residencia en el seno de la reducción,

"Que los hombres que están más cercanamente ligados por el concepto de küpal, lo están también por el legislación chilena y aunque las reducciones ya no existen en un sentido legal, la solidaridad legal entre miembros de lo que ahora son conocidas como comunidades indígenas persiste, a través del hecho de que los recursos gubernamentales y privados son distribuidos no a hogares aislados, 
sino a estas comunidades legalmente constituidas" (Course 2009: 67).

Precisa que existen "reducciones uni-küpal y multi-küpal" (Course 2009: 75), en las primeras predomina un patronímico (son además exógamas), y en las segundas más de uno (endógamas),

Hoy día Oño Oñoco consiste de treinta y dos familias, cuyas cabezas se consideran pertenecientes a cinco kiñe küpal distintos. Una de las principales consecuencias de esto es que, mientras una comunidad como Conoco Budi es exógama debido a que todos los hombres y las mujeres solteras comparten un küpal, una comunidad como Oño Oñoco no es exógama, y no es inusual que ocurran matrimonio entre sujetos de diferente küpal dentro de la misma comunidad" (Course 2009: 75).

Por último y en relación directa a nuestro asunto:

La noción de küpal también está vinculada a un aspecto formalizado de la onomástica, referido generalmente en mapudungun como lakutun. Esto se refiere a un hombre que da a su primogénito el nombre (üy) de su padre, o sea, el niño posee el nombre de su abuelo paterno... Dentro de la memoria, el otorgar el nombre del abuelo era acompañado con algún tipo de ritual, sobre el que me ha sido imposible recabar mayores detalles. Este rito ya no se realiza, pero una vasta mayoría de los hombres aún llama a su primogénito como sus propios padres" (Course 2009: 69).

¿Esta descripción, pertinente para el sistema reduccional en el Budi, lo es para la época pre-reduccional? Si la data etnográfica de $\mathrm{ABB}$ y la histórica para la Araucanía evidencia qué modelo era el del laku, la tesis central tanto de Faron (1969) (la no existencia de linajes antes del sistema reduccional) como la de Course (2009) (la imposición de la dualidad a los tres sistemas de sociabilidad) ${ }^{9}$ se ven reforzadas. La gracia del laku es que relativiza (o minimiza) el peso de la descendencia (no existe un patronímico), e impone la dualidad a una cadena (el patrilinaje) que sin ella no tendría fin.

Andrés Menard, 2007

La propuesta de Andrés Menard sobre üy, contenida en su tesis doctoral (Menard 2007), tiene dos registros. Por un lado, la lectura totémica del üy (cüga) a la manera de Latcham (1922); por otro, la política al modo de Boccara (2007). Como ya lo hemos señalado, ambas no serían pertinentes 
al basarse en la creencia de un üy compartido por más de dos sujetos que daría origen y sustento a un grupo totémico (Latcham) o a un grupo político (Boccara).

No obstante, hay una dimensión en la obra de Menard que nos parece relevante destacar (si se tiene en mente el modelo laku), se trata de la vinculación del $\ddot{u} y$ con la propuesta de Viveiros de Castro (2002), sobre la "identidad caníbal" -también desarrollada por Boccara (2007)- que permite aproximarse a la dimensión del "registro y del archivo mapuche",

“... el espacio parental dado opera como un espacio de alianzas $y$ contra-alianzas en potencia en la medida en que el Otro funciona como un Yo (caníbal) en potencia. El laku (o el cuga) correspondería a aquel resto canibalizado de la lógica caníbal, entendido como registro histórico heterogéneo y analogable a una idea ampliada de la escritura. De ahi que el laku pueda ser entendido como una forma de la escritura mapuche, o más bien, de sus mecanismos de registro y de archivo" (Menard 2010:2) ${ }^{10}$.

Este "registro y archivo" de intercambio de nombres contrasta con el intercambio de mujeres (aunque ambas tienen en común el ser formas de alianza),

"La primera crearia mediante el don de las mujeres un tiempo (en tanto tiempo construido y entendido como tiempo de una espera del contra-don) extendido sobre el plano sincrónico de las afinidades virtuales y realizadas, mientras que la segunda remitiría a la operación diacrónica (por referir a la distancia intergeneracional) de registro de las filiaciones construidas sobre ese mismo plano parental virtual" (Menard 2010:2).

Este el punto que nos parece central: la clave del $\ddot{u} y$ y de su donación (laku) es la capacidad de transformar la red filial en una suerte de alianza. Es lo que observaba Course (2009) en Isla Huapi: la tensión que introduce el sistema reduccional al redefinir la filiación bajo el manto genealógico (impuesto por el registro chileno), cuestión que anteriormente se evitaba a partir del manejo del nombre. Así para Menard,

Este modelo de nominación mapuche [laku] debe ser comprendido a la luz de su interacción y competencia con el modelo de registro y nominación estatal chileno. Para ello resulta interesante el fijar la atención en las formas de enunciación genealógica de aquellos escritores y dirigentes mapuches históricamente localizados en el 
momento de la instalación del régimen reduccional y de la máquina escritural chilena. Un caso es el de Aburto Panguilef, quien en 1914 escribia una suerte de presentación de su linaje, en el que aparece como punto inicial la figura de su abuelo Luis Aburto Ayñamco, de quien se subraya el carácter de aliado del gobierno chileno, alianza inscrita en el apellido Aburto que habría recibido del Comisario de Naciones homónimo. El segundo referente genealógico es su tio paterno Bernardo (Aburto) Namuncura, quien también se destaca por su intensa actividad política y burocrática, primero en el lado argentino como secretario de Callfucura y luego como "cacique agente" y aliado del gobierno chileno. El dato sintomático en esta presentación genealógica (y que caracteriza el tratamiento genealógico de la totalidad de la extensa obra aburtiana) es la casi ausencia de referencias a su padre Felipe Nahuelcura, la que podrá ser explicada tanto por una pregnancia del modelo de los laku y su "forclusión del nombre del padre" como por una preponderancia de los atributos politicos de los referentes genealógicos antes que por los atributos de consanguinidad. Sea como fuere, notemos cómo el esquema genealógico quiebra la linealidad vertical de una simple presentación filiativa" (Menard 2010: 2).

José Isla, 2009

Si para Faron (1969) el principio constitutivo de la vida reduccional es el patrilinaje, para Stuchlik (1999) una suerte de mixtura de grupos egocentrados y de filiación, para Course (2009) al menos tres redes de sociabilidad, para José Isla (2009), en cambio, es el lov, entendido como un grupo residencial patrilocal y exógamo. Fundado,

"sobre los lazos parentales que unen entre si a un conjunto de jefes de grupos domésticos, llamados generalmente ngenruka. Se trata de un grupo de hombres que actúa como núcleo «interior» del grupo residencial... estos hombres se relacionan entre si ya como peñi, si pertenecen a la misma generación, ya como malle si pertenecen a generaciones consecutivas, o como laku si pertenecen a generaciones alternadas. Las relaciones laku, malle y peñi configuran, por asi decirlo, la terminología que describe el núcleo «interno» del grupo residencial. Las categorias palu, lamngen y kuku, equivalentes femeninos de malle, peñi y laku respectivamente, complementan el paisaje del grupo residencial, a la vez que lo abren hacia las "proximidades»" (Isla 2009:34). 
Para Isla, el lov tiene una cara política en la medida que los ngenruka, "reconocen el liderazgo de uno de ellos, llamado longko ("cabeza»). El longko aparece como el actor principal en la articulación politica y ritual del grupo residencial con los otros grupos que conforman el espacio de las "proximidades». En la selección del longko concurren factores genealógicos y caracteristicas personales, entre las que sobresale el arrojo físico, la oratoria y la capacidad narrativa" (Isla 2009: 36).

De este modo el grupo doméstico es una "unidad socio-política básica al interior de las comunidades «reduccionales» pewenche".

Ahora bien, lo fundamental de esta propuesta está en "no dejarse llevar por una hipotética primacía de la consanguinidad como la clave constitutiva del grupo residencial". Justamente si se enfatiza en "la consanguinidad" se daría "pie a un error que ha entrampado la sociología mapuche por largo tiempo: la supuesta presencia de «linajes» entre los mapuche". ${ }^{11}$ Para el autor,

"la observación empirica indica que en los hechos la linea "agnática» que articula el lov se constituye en buena medida al margen de la consanguinidad. De otra parte, la línea "agnática» que representa el núcleo «interno" del grupo residencial, se ve sujeta a frecuentes fisiones y desplazamientos que borran los lazos de parentesco en un tiempo relativamente corto (no más de tres generaciones). El espacio de "cercanias» no resiste la introducción persistente de una distancia geográfica o social. De esta manera, nos parece claro que no es el lazo agnático el que crea el «interior» del grupo residencial exógamo, sino que es éste «interior» el que define lo que se entenderá por lazo agnático. Es la "cercania» fundada sobre una fuerte opción de residencia patrilocal la que produce la emergencia de un núcleo agnático y no al revés" (Isla 2009:36-37).

Dentro de este esquema, el territorio y la sociedad, "emergen entonces bajo una forma fuertemente concéntrica, no egocéntrica [a diferencia de Stuchlik] y sin el contrapeso de una influencia diametral como la que suponen los sistemas de parentesco binarios que escinden el campo social entre consanguíneos y afines" (Isla 2009: 29)

En esta propuesta, donde la residencial patrilocal funda sociológicamente el espacio de "cercanías"12, ¿cómo puede leerse la cuestión de üy y de su rito, el lakutún? Si al interior del lov las relaciones entre peñi y malle son 
relevantes, la relación laku sería "aún más fundamental” en la constitución del grupo residencial,

"En efecto, la transmisión de la identidad social entre los pewenche se produce preferentemente entre generaciones alternas. ${ }^{13}$ Asimismo, es en buena medida sobre los miembros de la generación de los "abuelos" que descansa la socialización y el aprendizaje cultural de los "nietos». En este contexto, las narraciones (nutram) que los abuelos transmiten a sus hijos y nietos constituyen el principal canal de transmisión de los saberes (kümün) y las disposiciones conductuales que dan forma a la identidad social del grupo residencial exógamo" (Isla 2009:35).

Y si en $\mathrm{ABB}$ los grupos residenciales exógamos intercambian mujeres al interior de la reducción, definida ésta como un "grupo local endógamo", entonces el "grupo residencial define el espacio de las "cercanías», el grupo local define el espacio de las "proximidades». Ambas instancias básicas de la sociedad mapuche de ABB, el grupo residencial exógamo y el grupo local endógamo, se constituyen y se actualizan en rituales performativos específicos. Es el caso del lakutun para la constitución del grupo residencial exógamo y del nguillatun para el grupo local endógamo" (Isla 2009:51).

La hipótesis de Isla entonces es que,

"Para un observador externo que disponga de una perspectiva diacrónica, el lov aparece conformado en torno a un núcleo de hombres emparentados por linea agnática y cuyos nombres propios [üy] permanecen en el lugar, alternando las generaciones, aunque cambien los grupos domésticos (ruka) donde se emplazan. De esta manera, este stock de nombres propios se identifica con el «lugar» donde habita el grupo residencial, configurando una suerte de identidad social del territorio. Asimismo, la temporalidad que la circulación de nombres propios masculinos imprime al lov no es lineal, sino reversible y circular. ${ }^{14}$ Esto muestra como, al interior del grupo residencial, la distancia (espacial y/o social) puede considerarse nula o carente de sentido, propiamente «insignificante». Por lo mismo, las relaciones sociales que se fundan sobre la distancia, como la alianza matrimonial o la agresión chamánica, quedan por definición fuera del grupo residencial y sólo resultan comprensibles en cuanto realizadas al "exterior» o desde el "exterior"" (Isla 2009:40). 


\section{Conclusión}

Pensamos que los antecedentes de $\mathrm{ABB}$ permiten clarificar el enigma del sistema de los nombres vía el modelo del laku, descartándose el modelo aleatorio sostenido por los jesuitas desde el siglo XVII. La reflexión de Guevara (1925), en las primeras décadas del siglo XX, y las más recientes de Boccara (1999 y 2007), Course (2009), Isla (2009) y Menard (2007 y 2010), permiten ligar el modelo del laku, o de la donación, a los enigmas de la filiación y de la residencia mapuche. En ambos casos los vínculos "nominales" son el intento por "politizar" algo que puede ser visto y "tematizado" como vínculos "naturales". En otras palabras, los mapuches pre-reduccionales transformaban la filiación en un asunto de alianza por medio del laku, con la implantación del sistema reduccional la filiación gana fuerza (como linaje: Faron 1969), pero siempre en tensión, sea por la persistencia en algunas áreas del laku, sea por las redes de alianza y de la amistad, sea por los vínculos residenciales. Pero, el enigma quedaría ahora nuevamente en suspenso si pusiéramos en relación el modelo laku con el kuku, este último abre interrogantes sobre los sentidos de la estructura de parentesco y sus consecuencias en el orden de las significaciones de género; si las mujeres portan nombres donados desde su linaje y sólo los transmiten dentro del grupo de patriparientes al cual llegan por la regla de exogamia, entonces tendríamos que dilucidar el tipo de posición que la sociedad mapuche asignó a sus mujeres. Éstas en su "volatilidad" también remiten con sus nombres a sus abuelas y con ellas a todas sus parentelas femeninas "vivas" y "muertas". De este modo, la revisión que hemos realizado parece sugerir que los dos modelos funcionan como tránsitos paralelos ¿y complementarios? Esta nueva pregunta deberá ser respondida a futuro.

\section{Notas}

1 Abuela paterna, la abuela materna: llalla (también la esposa del hermano de la madre y la esposa del hijo del hermano de la madre).

2 "En la terminología mapuche del parentesco, un EGO (masculino o femenino) llamará «laku» al padre de su padre (FF) y a los hermanos reales o clasificatorios del padre de su padre. Por su parte, un EGO (masculino o femenino) llamará «kuku» a la madre de su padre, y genéricamente a las esposas de aquellos varones que se ubican en la posición «laku». Se trata, como la mayoría de los términos del parentesco mapuche, de términos de utilización recíproca. En consecuencia, un varón llamará «laku» a los hijos e hijas de sus hijos (SS, SZ) y a los hermanos reales o clasificatorios de los hijos de sus hijos (BSS, BSZ). Por su parte, una mujer llamará "kuku» a los hijos e hijas de sus hijos (SS, SZ) y a los otros miembros de la línea agnática de su marido pertenecientes a la generación de los hijos de sus hijos. Además de todo lo anterior, un mapuche identificará como "laku» al individuo del cual ha recibido su nombre propio" (Isla 2009:18).

3 La fuente más relevante son un total de 83 testamentos de mapuches, que van desde 1855 a 1913 (ver "Testamentos mapuche-lafkenche de la provincia de Arauco (1856-1913”), Proyecto Fondecyt 1050616, Borrador, marzo del 2008. 
4 Havestadt (1883): "Lacu: dos personas que tienen el mismo nombre o el mismo apellido: Asimismo. Abuelo y nieto por parte del padre. Tener el mismo nombre".

5 “... el tótem no es el antepasado, sino el animal o ser con quien éste [el antepasado] formó alianza y con quien contrajo lazos de consanguinidad. En el totemismo araucano estos dos seres [el tótem y el antepasado] no se confunden. Cada uno tiene su nombre distinto, sus atributos son diversos y cada cual recibe un culto separado. En ningún caso se confunde el antepasado, fundador de la tribu, con el tótem...El tótem no se presenta en la forma de un antepasado consanguíneo de quien se deriva el clan. Era más bien el ser tutelar y protector del fundador, con quien estaba aliado para resguardar los intereses y para procurar el bienestar mutuo de los descendientes de ambos. De este ser, el clan deriva su nombre, a él le tributaban respeto y estimación, pero no lo adoraban. Conjuntamente con el padre del clan, vigilaba por el bienestar del grupo, pero los araucanos jamás confundían las dos personalidades y para cada una tenían nombres distintos. El antepasado tradicional a veces mítico, pero jamás deificado, tenía la denominación especial de Pillán. Este nombre se deriva de la voz püllu o pilli —espíritu, al cual [305] los araucanos siempre conceptuaban en forma corpórea aunque invisible-....no era determinado y único, sino múltiple, y variaba de un grupo totémico a otro. Era el antepasado fundador del clan, originador del tótem, por cuanto era él que debía elegir el aliado epónimo que en seguida se constituía en tótem.

El tótem, por otra parte, se llama cüga o cünga; pero esta institución sólo llamó la atención de los cronistas como un sistema de apellidarse..." (Latcham 1922: 305-306).

6 Véase Faron (1969) y últimamente Boccara (2007) y Course (2009).

7 1991: 82.

8 De allí que Course (2009: 74) señale que "el término kiñe küpal se acerca al nivel de organización que Faron denomina linaje mínimo".

9 “Esta manera de pensar el intercambio, y de elaborar el mismo, es común a muchos aspectos..." (Course 2009: 55).

10 Para mayor desarrollo ver su tesis doctoral (Menard 2007), en especial el capítulo II de la tercera parte.

11 Para Isla esto tendría una validez incluso más allá de ABB: "No existe nada en ABB ni remotamente cercano a las estructuras sociales segmentarias descritas por las influyentes monografías británicas dedicadas a los sistemas políticos africanos. Y creemos poder extender sin mayores problemas esta inexistencia de instituciones segmentarias al conjunto del mundo mapuche” (Isla 2009:61).

12 De este modo para los mapuche no existiría "una diferencia radical entre distancia física y distancia social, la formas sociales aparecen en buena medida ante los ojos del actor como formas de tratamiento de la distancia y la proximidad". En términos "parentales": "nuestra intuición de que entre los mapuche la residencia recubre la filiación, no queda lugar para pensar los linajes como entes supralocales, como fantasmagóricos patrilinajes desacoplados del patrón de residencia patrilocal” (Isla 2009: 59).

13 "Los nombres propios mapuche ( $g \ddot{u ̈ i}$ ) se asocian estrechamente al püllü. En buena medida, el nombre propio identifica socialmente al püllü más que a un individuo específico. Por lo mismo, los nombres propios masculinos pertenecen al «lugar», formando un conjunto finito estable en el tiempo, recibido de los antepasados y transmitido a los descendientes, que permite en la práctica cotidiana identificar al grupo residencial y a sus miembros sin necesidad alguna de recurrir a un patronímico a la manera hispana. Siempre los varones que habitan el «lugar» poseen los mismos nombres propios, heredados en generaciones alternadas" (Isla 2009: 48-49).

${ }^{14}$ En otro lugar Isla insiste en este vínculo tempo-espacial: "Un «lugar», además, sujeto a una temporalidad reversible, donde los habitantes presentes comparten la identidad de los habitantes pasados y donde el tiempo se repliega continuamente sobre sí mismo" (Isla 2009: 42).

\section{Bibliografía}

Alonqueo, M. 1984. Mapuche ayer-hoy, Editorial San Francisco, Temuco.

Augusta, F. J. 1907. ¿Cómo se llaman los araucanos?. Imprenta San Francisco, Valdivia.

Boccara, G. 1999. "Etnogénesis mapuche: resistencia y restructuración entre los indígenas del centro-sur de Chile (siglos XVI-XVIII)". Hispanic American Historical Review 79: 425-461. 
Boccara, G. 2007. Los vencedores. Historia del pueblo mapuche en la época colonial. Universidad de Chile y Universidad Católica del Norte y HAM, Santiago.

Catriquir, D. 1990. "El nombre personal en la sociedad y cultura mapuche". Actas de Lengua y Literatura Mapuche 4: 257-275.

Catriquir, D. y Durán, T. 2007. "Mapun Üy: el nombre personal en la sociedad y cultura mapuche. Implicancias étnicas y sociales". En: Patrimonio Cultural Mapuche. Derechos sociales y patrimonio Institucional Mapuche, T. Durán, D. Catriquir, (comp.), Vol.III: 377394. Ediciones UC, Temuco.

Course, M. 2009. Mapuche Ni Mongen. Individuo y Sociedad en el Sur de Chile. Manuscrito en proceso de publicación en poder del autor.

Dillehay, T. 1990. Araucanía: presente y pasado. Editorial Andrés Bello, Santiago.

Faron, L. 1969. Los mapuches, su estructura social. Instituto Indigenista Interamericano, México.

Faron, L. 1977. Antüpaiñamko. Moral y ritual mapuche. Ediciones Mundo, Santiago.

Febres, A. 1765. Arte de la lengua general del Reyno de Chile. Lima.

Foerster, R. 1980. Estructura y funciones del parentesco mapuche: su pasado y presente. Tesis para optar al grado de Licenciado en Antropología, Departamento de Antropología, Universidad de Chile. Santiago.

Foerster, R. 2004. ¿Pactos de sumisión o actos de rebelión? Una aproximación histórica y antropológica a los mapuches de la costa de Arauco, Chile. Tesis para optar al grado de doctor en Antropología. Universidad de Leiden, Holanda.

Foerster, R. y Gundermann, H. 1993. "Acerca del nombre propio mapuche”. Nütram 31: 41-55.

Guevara, T. 1925. Historia de Chile. Chile prehispánico. Universidad de Chile-Balcells, Santiago.

Havestadt, B. 1883. Chilidugun sive tractatus linguae chilensis. Leipzig.

Isla, J. 2009. Un lugar en el mundo. Manuscrito en posesión del autor. 
Jiménez, J. F. 2002. Matrilinealidad versus patrilinealidad. La obra de Félix José de Augusta y la polémica acerca de la filiación entre los Reche Mapuche. Centro de Documentación Patagónica. Departamento de Humanidades, Universidad Nacional del Sur.

Latcham, R. 1922. La organización social y las creencias religiosas de los antiguos araucanos. Publicaciones del Museo de Etnología y Antropología de Chile, Santiago.

Menard, A. 2007. "Pour une lecture de Manuel Aburto Panguilef (18871952). Ecriture, délire el politique en Araucanie post-reductionnelle". Tesis para optar al grado de doctor en Antropología. Escuela de Altos Estudios, París.

Menard, A. 2010. Notas sobre el nombre propio mapuche. Manuscrito en posesión del autor.

Silva, O. 1984. "En torno a la estructura social de los mapuches prehispánicos”. CUHSO 1: 89-115.

Stuchlik, M. 1999. La vida en mediería. Soles Ediciones, Santiago.

Valdivia, L. 1684. Arte, y gramática general de la lengua que corre en todo el Reyno de Chile, Sevilla.

Viveiros de Castro, E. 2002. "O nativo relativo". Mana 8(1): 113-148. 
露 